\title{
Research on Low-density Cross-border Support Technology For Large-section Coal Roadway in Shallow-buried Thick Coal Seam
}

\section{Shiping Yan}

Shenmu Ningtiaota Mining Company,Shaanxi Coal and Chemical Industry Group

feng guo ( $\sim$ guo_feng@cumt.edu.cn)

China University of Mining and Technology - Xuzhou Campus: China University of Mining and

Technology

\section{Fei Chen}

Shenmu Ningtiaota Mining Company,Shaanxi Coal and Chemical Industry Group

\section{Yuxiang Cao}

Shenmu Ningtiaota Mining Company,Shaanxi Coal and Chemical Industry Group

\section{Zhe He}

China University of Mining and Technology - Xuzhou Campus: China University of Mining and Technology

\section{Research Article}

Keywords: coal road, thick coal seam, low density, cross-boundary support

Posted Date: July 22nd, 2021

DOl: https://doi.org/10.21203/rs.3.rs-553994/v1

License: (c) (i) This work is licensed under a Creative Commons Attribution 4.0 International License. Read Full License 


\section{Abstract}

The slow excavation speed of coal roadways has always been a key factor restricting the safe and efficient production of large-scale coal mines in China, and the problem of unbalanced mining replacement caused by this is widespread. This paper takes the $\$ 1231$ heading face of the Ningtiaota coal mine of Shaanxi Coal and Chemical Industry Group as the research object, analyzes the characteristics of the stress evolution of coal roadway driving, reveals the principle of low-density crossborder support, and proposes a low-density cross-border support plan. . Using FLAC 3D to study the roadway stress-displacement evolution law of the new support scheme during the driving and mining phases, the results show that the peak stress during the driving is $5.3 \mathrm{Mpa}$, and the coal pillar side stress concentration is the most obvious during the mining period, with the peak value being $7.9 \mathrm{Mpa}$. The moving distances of the two banks are both $10 \mathrm{~mm}$, which verifies the feasibility of low-density crossborder support. Field application shows that during roadway excavation, the amount of roof subsidence and the displacement of the two sides are $9 \mathrm{~mm}$ and $11 \mathrm{~mm}$, respectively, and the development depth of roof cracks is controlled within $0.5 \mathrm{~m}$. The overall control effect is good, and the speed of coal roadway driving is increased by $77.19 \%$ compared with the original. The new support builds a thick roof anchor structure to ensure the safety and stability of the roadway. At the same time, by reducing the number of bolts, the bolt support time has been greatly reduced, effectively alleviating the tight situation of mining replacement, and providing solutions for mines under the same conditions.

\section{Introduction}

90\% of my country's coal resources are mined by wells (Kang et al., 2020; Li et al., 2019; Liang et al., 2021; Yang et al., 2021).In recent years, with the reform of my country's energy industry and the development of national digital informatization, the advancement of coal mining faces has continued to increase under the research of the vast number of scientific and technological workers, and intelligence represented by mining areas such as Huangling and Yushen have emerged. As a leading project for coal mining, due to special reasons such as the complex engineering environment, the driving efficiency of the driving face is seriously lagging, and the proportion of mining is seriously out of balance. According to statistics, the average coal mining team and the fully mechanized mining team are Ratio3.1:1.0(Kan et al., 2021; Wang et al., 2019; Yang et al., 2021).Therefore, the safe and efficient advancement of the tunneling face is one of the key issues that restrict the safe and efficient mining of coal.

Ma Peng et al(Ma et al., 2020)By analyzing the time-efficiency characteristics of each process of tunneling, optimizing the construction technology, and proposing a rapid tunneling method for deep tunnels, the tunneling speed of Menkeqing Coal Mine was increased to $1080 \mathrm{~m} / \mathrm{month}$.Bin Tang et al(Tang et al., 2020)Through theoretical calculation, numerical simulation, stress analysis, and other means, TBM was successfully applied to underground mine tunnels, and support optimization schemes for process equipment were proposed, which verified the feasibility of field application.Xie, Zhengzheng et al(Xie et al., 2018)Given the unique conditions of the Hulusu Coal Mine, the time-effect characteristics of the support were analyzed, and the high-preload and long-anchoring technology were proposed to 
effectively control the deformation and development of the surrounding rock while increasing the excavation efficiency by $85.3 \%$. The above scholars have improved the efficiency of the excavation through the optimization and adjustment of the excavation support technology, which has important reference significance for efficient and rapid excavation. According to statistics, cutting takes up 20 $30 \%$ of the cycle time in the coal tunnel excavation process, and the installation time of bolts (cables) takes up $50 \sim 60 \%$ of the cycle time. Supporting time is much higher than cutting time, which leads to coal mines. The unbalanced mining ratio is a universal problem that restricts the safe, high-yield,and efficient production of coal mines(Feng et al., 2019; Xie et al., 2019; Yang et al., 2019).

Shenmu Ningtiaota Mining Company, Shaanxi Coal and Chemical Industry Group, located in Shenmu County, Yulin City, Shaanxi Province (Fig. 1), is a large modern coal mine in my country's Shanxi, Shaanxi, and Monte large-scale coal fields, with an approved production capacity of 18 million tons per year. The shearer double-lane tunneling, with average footage of $720 \mathrm{~m} / \mathrm{month}$, its tunneling efficiency is seriously mismatched with its production capacity, and the continuation of mining is seriously unbalanced. Aiming at the problem of unbalanced mining and excavation caused by complex supporting procedures and excessive time-consuming in Ningtiaota Coal Mine, this paper uses the principle of cross-boundary support for coal roadways as guidance and uses a combination of numerical simulation and field practice to assist Ningtiaota Coal Mine S1231 The existing excavation and support schemes of the transportation lane are optimized and compared, and the low-density and high-efficiency support optimization scheme under the guarantee of the existing support effect is proposed. And verify its on-site application effect.

\section{Engineering Background}

The test site of this project is located in the auxiliary transportation lane of Ningtiaota Mining Company S1231, Shenmu City, Shaanxi Province (Fig. 2). The working face is located in the south wing mining area of the 2-2 coal seam. There is an $18 \mathrm{~m}$ coal pillar between the test roadway and the $\$ 1230$ working face, and the average coal seam thickness is $6.95 \mathrm{~m}$, using the total collapse method to manage the roof. The roadway is arranged along the coal seam floor, the top coal thickness is $2.85 \mathrm{~m}$, the roadway depth is 126$200 \mathrm{~m}$, the roadway height is $4100 \mathrm{~mm}$, the roadway width is $5700 \mathrm{~mm}$, and the cross-section area is $23.37 \mathrm{~m} 2$. It is typical thick-top coal and large-section roadway. The basic top is coarse-grained siltstone with an average thickness of $6.58 \mathrm{~m}$; the immediate top is carbonaceous mudstone with an average thickness of $0.2 \mathrm{~m}$; the immediate bottom is coarse-grained gray siltstone and gray carbonaceous mudstone with an average thickness of $5.78 \mathrm{~m}$ (Table 1 ).

Table 1 The nature and thickness of the rock 


\begin{tabular}{|lll|}
\hline & Rock & Thickness $/ \mathrm{m}$ \\
\hline Basic top & Siltstone & 6.58 \\
\hline Direct top & Carbonaceous mudstone & 0.2 \\
\hline Coal seam & 2-2 Coal seam & 6.95 \\
\hline Basic bottom & Siltstone & 5.78 \\
\hline
\end{tabular}

As shown in Fig. 3, the roof is supported by 6 anchor rods with a length of $2.0 \mathrm{~m}$ and a diameter of $20 \mathrm{~mm}$ and a row spacing of $1000 \mathrm{~mm}$ and three anchor cables with a length of $7 \mathrm{~m}$ and a diameter of $17.8 \mathrm{~mm}$ and a row spacing of $4500 \mathrm{~mm}$. The existing support effect is relatively good, but the support is a timeconsuming Longer length, more construction personnel, and greatly increased support costs. In addition, the construction of anchor cables affects important links such as main and auxiliary transportation, restricting the efficiency of excavation and transportation, and there are potential safety hazards (Fig. 4).

\section{Principles Of Cross-boundary Support For Coal Roadways 3.1 Time-effect characteristics of coal roadway support}

At the initial stage of roadway excavation, the empty roof area has a certain self-stability performance under the constraints of the support area and the end coal body within a certain period of time. This area is called the time-dependent self-stability area(Xie et al., 2019; Yang et al., 2019). Its self-stabilization performance is positively correlated with the strength and thickness of the rock layer and negatively correlated with the magnitude of the stress and the unloading area. The timely support of the area within the effective self-stabilization time can greatly reduce the degree of rock mass damage.

As shown in Fig. 5, after the roadway is excavated and unloaded, the supporting pressure in front of the coal body undergoes a repelling evolution over time. The reason is that the cracks in the shallow part of the coal body gradually develop and shift to the deep part. While expanding the damaged area, The stress continuously shifts to the deep part, causing the stress superposition coefficient to increase. Thus, in the empty region from the top support timely completion aging stability and rapid excavation stress driving effect can be achieved, so that the support area is always under the roof stress peak stress, thereby reducing damage to rock, to ensure full support member Sex.

Site investigation found, Ningtiaota coal mineS1231 seam face where the Tunneling hardness, good storage conditions, after excavating the tunnel, good stability from coal, coal front supports driving pressure over time is very weak, the top plate homeostatic up to $6 \mathrm{~m}$ from above, the top coal thickness of $2.5 \mathrm{~m}$, roof strata is very stable, high reliability, the possibility of having a large inter-row spacing of embodiment and efficient support of a low density.

\subsection{Transboundary support mechanism}


In engineering applications and laboratory experiments, it is often found that there is a crack ring near the anchorage boundary, that is, the anchor rod reinforcement range is small, and the anchor point is located near the crack ring boundary, which is called critical support or inbound support. The essence of support is to control rock deformation, reduce rock damage and crack expansion, and ensure the stability of surrounding rock(Xie et al., 2019; Yang et al., 2020).

Cross-boundary support means that the bolt support penetrates the key circle layer, crosses the cracked circle layer, and controls the cracked circle layer in the shallow area of the effective length of the bolt, to ensure the integrity of the deep surrounding rock and fully mobilize the performance of the deep surrounding rock, Suppress shallow deformation, increase the thickness of the anchoring layer, and have the structural effect of resisting stress disturbance and increasing safety and reliability.

Ningtiaota Coal MineS1231 The roof coal body of the driving face has high hardness and good integrity. The roof rock body is mostly coarse sandstone and siltstone. Based on the comparison of the above geological conditions and the effect of the original support plan on-site, it can be considered to extend the length of the bolt to ensure the anchor layer. At the same time of thickness, the number of bolts is reduced, to realize the improvement of support efficiency, and then provide a design basis for the proposal of low-density cross-border support.

\section{Numerical Model And Scheme}

\subsection{FLAC ${ }^{3 \mathrm{D}}$ numerical model and boundary conditions}

FLAC ${ }^{3 \mathrm{D}}$ numerical model (Fig. 6). The length, width, and height of the model are $230 \mathrm{~m}, 180 \mathrm{~m}$, and $45.5 \mathrm{~m}$ respectively. The upper boundary load is calculated at a mining depth of $163 \mathrm{~m}$, and the top of the model is a free surface. The gravity of the rock above the top of the model is applied to the upper boundary, that is, vertical stress of $4.075 \mathrm{MPa}$ is applied at the highest point of the model. The bottom boundary of the model is fixed in the vertical direction, and the left and right boundaries are fixed in the horizontal direction. This model uses Moore Coulomb's criterion.

\subsection{Simulation scheme}

This simulation takes the $\mathrm{S} 1231$ auxiliary transport road as the research object and uses low-density cross-border support technology to simulate the stress-displacement evolution law of roadways in different periods.

Based on the principle of cross-boundary support for coal tunnels, overall consideration is given to the self-stability and roof lithology of the roadway in Ningtiaota Coal Mine S1231 heading face, using the principle of low-density cross-boundary support and field experience, the following scheme is proposed.

Low-density cross-border support scheme: The roof consists of 4 left-handed non-longitudinal rebar bolts with a diameter of $20 \mathrm{~mm}$ and a length of $2.5 \mathrm{~m}$ in each row, with a row spacing of $1600 * 1200 \mathrm{~mm}$. In 
addition, one anchor cable with a diameter of $17.8 \mathrm{~mm}$ and a length of $7 \mathrm{~m}$ is constructed for each row, which is arranged above the centerline of the roadway with a row spacing of $3000 \mathrm{~mm}$ (Fig. 7). On the non-mining side of the roadway, 3 round steel bolts with a diameter of $16 \mathrm{~mm}$ and a length of $1.8 \mathrm{~m}$ shall be constructed in each row, with a row spacing of $1200 * 1200 \mathrm{~mm}$. Three FRP bolts with a diameter of $18 \mathrm{~mm}$ and a length of $1.4 \mathrm{~m}$ are constructed in each row on the mining side, with a row spacing of $1200 * 1200 \mathrm{~mm}$.

Simulate the stress-displacement evolution cloud diagram of the surrounding rock of the lower roadway during the three periods of the driving period, S1230 working face (primary mining), and S1231 working face (secondary mining).

\section{Simulation Results And Discussion}

\subsection{Analysis of vertical stress distribution law of roof during tunneling}

As shown in Fig. 8, the model is sliced along the roof of the coal seam, and the vertical stress distribution at different positions before and after the head is analyzed. The colors in the figure from red to blue indicate that the vertical stress gradually increases. There is a "C"-shaped stress concentration zone at about $0-15 \mathrm{~m}$ head-on in front of tunneling, and there is a stress superimposed zone greater than 4.0Mpa on the side of the coal pillar of the roadway during the double-lane tunneling process.

The model roadway has a total length of $180 \mathrm{~m}$. When driving $90 \mathrm{~m}$, the vertical stress analysis is carried out at 5, 15, 25, and 35m front and rear respectively. As shown in Fig. 9, the $5 \mathrm{~m}$ front and rear of the driving is a severely disturbed area, and the stress concentration intensity is more than $5.3 \mathrm{Mpa}$. ; The front $15 \mathrm{~m}$ is the disturbance mitigation zone; the front $25 \mathrm{~m} \sim 35 \mathrm{~m}$ is in the excavation disturbance stable zone, which is not affected by mining.

The vertical stress distribution behind the front is similar to the front. Stress concentration occurs on the left and right sides of the roadway, and the influence range gradually increases as it is far from the head of the tunnel. The stress concentration in the area $15 \mathrm{~m}$ away from the head of the tunnel gradually weakens. Within $1.5 \mathrm{~m}$ of the shallow surface of the two sides, there is a sudden unloading area of roadway excavation stress. This phenomenon is often accompanied by the phenomenon of fragmentation. There is a stress concentration phenomenon at $8 \mathrm{~m}$ above the top plate at the front end. As the distance from the front end increases, the concentrated stress gradually decreases.

As shown in Fig. 10, during the double-lane tunneling of the new scheme, there are "C-shaped" vertical stress distribution areas at different positions above the roof of the working face. The stress difference is $0.02 \mathrm{Mpa}$ at a distance of $1.5 \sim 2.5 \mathrm{~m}$ above the roof; the distance is $2.5 \sim$ At $3.5 \mathrm{~m}$, the stress difference is $0.2 \mathrm{Mpa}$; at the distance of $3.5 \sim 4.5 \mathrm{~m}$, the stress difference is $0.05 \mathrm{Mpa}$. Therefore, it is concluded that the excavation engineering activities have caused different levels of disturbance effects on the roof, which 
also explains the low-density cross-boundary roof from the front. The support meets the existing roadway control requirements.

As shown in Fig. 11, with the head-on position as the origin of the coordinates, the vertical stress of the survey lines at $0 \mathrm{~m}, 1 \mathrm{~m}, 2 \mathrm{~m}, 3 \mathrm{~m}, 4 \mathrm{~m}$, and $5 \mathrm{~m}$ on the roof of the roadway is monitored. It is found that the vertical stress changes significantly within the range of $20 \mathrm{~m}$ from the front of the roadway. In the range beyond $20 \mathrm{~m}$, the vertical stress is relatively stable and changes slowly.

After the roadway is excavated, the vertical stress of the roof is significantly reduced due to the pressure relief effect, and its magnitude is much smaller than the original rock stress. Taking the $0 \mathrm{~m}$ measurement line above the roof as an example, the stress suddenly increased to $-4.3 \mathrm{Mpa}$ at $20 \mathrm{~m}$ behind the head, and slowly increased to $-4.7 \mathrm{Mpa}$ at the front, while the stress at $20 \mathrm{~m}$ in front of the head gradually decreased, and the decrease was reduced from $20 \mathrm{~m}$. The internal stress of $\sim 40 \mathrm{~m}$ decreases slightly, approaching $4.5 \mathrm{Mpa}$, which is the original rock stress at this moment. Within the range of $40 \mathrm{~m} \sim 90 \mathrm{~m}$, the stress gradually stabilizes to about $-4.5 \mathrm{Mpa}$.

\subsection{Analysis of the vertical displacement change of the roadway during the stoping period}

1)Once mining

After one mining, the displacement and deformation of the roadway are shown in Fig. 12(a). The maximum deformation of the roadway roof is $0.5 \mathrm{~mm}$, and the bottom deformation is $1.2 \mathrm{~mm}$. Due to the influence of the goaf on the right, the left and right sides are asymmetrically deformed. The deformation of the left side is $0.25 \mathrm{~mm}$, and the deformation of the right side is $0.5 \mathrm{~mm}$.

Displacement and deformation analysis of the roadway roof is sliced, as shown in Fig. 12(b). The displacement and deformation of the ultra-front end of the roadway are the same as the deformation at the initial stage of driving, both within $0.5 \mathrm{~mm}$, and the deformation near the front end exceeds $1 \mathrm{~mm}$. With the gradual influence of one mining operation, the deformation of the roadway gradually increases. The peak value is $1.5 \mathrm{~mm}$ or more.

After a mining operation, the vertical stress distribution of the roadway is rough as shown in Fig. 12(c). The stress concentration on the coal pillar side reaches $4.54 \mathrm{MPa}$, which is 1.14 times the original rock stress. The stress in the goaf on the right is about $0.07 \mathrm{MPa}$. In addition, stress concentration occurred at the super front end of the working face on the right side, reaching $4.5 \mathrm{MPa}$.

2)Secondary mining

To study the impact of secondary mining on the $\mathrm{S} 1231$ tunneling face, the $\mathrm{S} 1231$ face was mined at 0.8 $\mathrm{m}$ each time. After 50 steps, the mining was performed again. After $89.6 \mathrm{~m}$ was mined, the calculation was completed to balance. 
As shown in Fig. 13(a), the maximum displacement and deformation of the roof after the stoping of this working face is $10 \mathrm{~mm}$, the left side deforms $2.5 \mathrm{~mm}$, the right side deforms $7.5 \mathrm{~mm}$, and the bottom plate deforms about $2.5 \mathrm{~mm}$.

As shown in Fig. 13(b), there will be three main stress concentration areas after the mining face, the stress disturbance area in front of the work face, the stress distribution area of the coal pillar structure, and the stress distribution area on the side of the goaf, and the stress on the side of the coal pillar. The peak concentration peak is the largest, which can reach 7.9 MPa; the peak stress peak at the super front end of the working face is second, at about $22.5 \mathrm{MPa}$; the peak stress concentration peak in the goaf area on the right is the smallest. Except for a stress concentration area in the middle of the goaf area, most of them are Original rock stress.

\subsection{Discussion}

During tunneling, the front and back $5 \mathrm{~m}$ range is the stress fluctuation area, and the $5 \sim 15 \mathrm{~m}$ is the stress adjustment area. After $15 \mathrm{~m}$, it gradually approaches the original rock stress area. It can be seen that the coal body has higher strength and better integrity, so the stress transfer range is smaller. From the perspective of the layout of the stress measurement line, the deep stress of the roof within $20 \mathrm{~m}$ behind the head has a larger increase of $0 \sim 2 \mathrm{~m}$, and the maximum increase at $0 \mathrm{~m}$ is as high as $2.3 \mathrm{Mpa}$. The stress fluctuation range of the area above $2 \mathrm{~m}$ is small. This phenomenon is explained from the front. The shallow area within $2 \mathrm{~m}$ of the roof is an important area to control the integrity and stability of the roof, and the design length of the anchor rod in the new scheme just achieves the cross-border support effect, and successfully builds a thick anchor layer.

After one mining, the maximum deformation of the roof of the roadway is only $0.5 \mathrm{~mm}$, the deformation of the bottom plate is $1.2 \mathrm{~mm}$, the deformation of the left side is $0.25 \mathrm{~mm}$, and the deformation of the right side is $0.5 \mathrm{~mm}$. After the second mining, the deformation of the roadway roof reaches $10 \mathrm{~mm}$, the left side deforms $2.5 \mathrm{~mm}$, the right side deforms $7.5 \mathrm{~mm}$, and the bottom plate deforms about $2.5 \mathrm{~mm}$. Combined with the cross-border anchoring mechanism(Xie et al., 2018), the results show that after the excavation of the tunneling project, the stress in the shallow part of the surrounding rock gradually increases. After the shallow surrounding rock produces cracks, the stress gradually transfers to the deep part, causing further extensive damage. The cross-border anchoring and supporting technology increases the length of the anchor rod under the premise of high prestress, which makes the development of shallow cracks slow during tunneling, and the degree of crack development is greatly reduced. In the later stage of mining disturbance, the roof has strong bearing performance and high integrity, so it can effectively control the deformation of the roadway.

Numerical simulation results show that the low-density cross-border support technology has a positive effect on the surrounding rock control of the S1231 tunneling face of the Caragana Tower, achieving good results, and can be tested on-site.

\section{Field Application Effect Analysis}




\subsection{Tunneling efficiency analysis}

During the promotion and application of the new support plan in the S1231 tunneling face, it will be carried out by 1 maintenance class and 2 production shifts. The cycle footage is $10 \mathrm{~m}$, and each production shift can complete 3 production cycles. A total of 7.5 cycles per month can be carried out. The regular cycle rate is calculated at $90 \%$. The daily footage is $67.5 \mathrm{~m}$. After considering each major cycle $(75 \mathrm{~m})$, the mine needs to carry out bottom-drawing work. At this time, the cutting and support will be stopped. Calculated based on 21 days of normal work per month, the average excavation rate is $1417.5 \mathrm{~m} /$ month (double lanes), which is $77.19 \%$ higher than the original excavation speed of the mine $(800 \mathrm{~m} /$ month). The original support of the mine was changed to low-density large-bolt high-efficiency support, and the speed of roadway excavation was significantly improved, which alleviated the problem of unbalanced mining in the mining area.

Table 2

Time-consuming table of cyclic construction process

\begin{tabular}{|c|c|c|c|c|}
\hline Number & Process & Operation method & $\begin{array}{l}\text { Assignment } \\
\text { order }\end{array}$ & $\begin{array}{l}\text { Time } \\
\text { /min }\end{array}$ \\
\hline 1 & $\begin{array}{l}\text { Moving machine, Laying net, } \\
\text { Lifting beam }\end{array}$ & $\begin{array}{l}\text { Anchor rod drill + } \\
\text { Manual }\end{array}$ & $\begin{array}{l}\text { Sequential } \\
\text { operation }\end{array}$ & 3 \\
\hline 2 & Cut Coal 5m & Continuous Miner & \multirow{2}{*}{$\begin{array}{l}\text { Parallel } \\
\text { operation }\end{array}$} & \multirow[t]{2}{*}{50} \\
\hline 3 & Roof Support & $\begin{array}{l}\text { Anchor rod drill + } \\
\text { Manual }\end{array}$ & & \\
\hline 4 & $\begin{array}{l}\text { Continuous miner and bolter } \\
\text { transfer }\end{array}$ & $\begin{array}{l}\text { Continuous miner + } \\
\text { Bolter }\end{array}$ & $\begin{array}{l}\text { Sequential } \\
\text { operation }\end{array}$ & 8 \\
\hline 5 & $\begin{array}{l}\text { Moving machine, Laying net, } \\
\text { Lifting beam }\end{array}$ & $\begin{array}{l}\text { Anchor rod drill + } \\
\text { Manual }\end{array}$ & $\begin{array}{l}\text { Sequential } \\
\text { operation }\end{array}$ & 3 \\
\hline 6 & Cut Coal 5m & Continuous Miner & \multirow{2}{*}{$\begin{array}{l}\text { Parallel } \\
\text { operation }\end{array}$} & \multirow[t]{2}{*}{50} \\
\hline 7 & Roof Support & $\begin{array}{l}\text { Anchor rod drill + } \\
\text { Manual }\end{array}$ & & \\
\hline 8 & $\begin{array}{l}\text { Continuous miner and bolter } \\
\text { transfer }\end{array}$ & $\begin{array}{l}\text { Continuous miner + } \\
\text { Bolter }\end{array}$ & $\begin{array}{l}\text { Sequential } \\
\text { operation }\end{array}$ & 8 \\
\hline Total & & & & 122 \\
\hline
\end{tabular}

The small-cycle construction process of the new support plan is shown in Table 2. This optimized plan greatly shortens the support operation time, makes the roof anchor rod and cable support, and the excavation cutting work parallel improves the construction efficiency and saves construction time. The average cycle time is 122 minutes.

\subsection{Analysis of mine pressure monitoring data}


(1) Roadway surface displacement monitoring

In the implementation of the new S1231 program, test stations W1 and W2 are arranged with a mileage of $50 \mathrm{~m}$ and $300 \mathrm{~m}$ respectively. The cross-section method is used to monitor the amount of roof subsidence and the amount of convergence of the two sides. The monitoring results are shown in Fig. 14.

From the surface displacement monitoring results in Fig. 14, it can be seen that the tunneling stress adjustment range is about $150 \mathrm{~m}$, of which the first $50 \mathrm{~m}$ is a relatively severe adjustment period. As the distance increases, the surface displacement shows a rapid increase to a slow increase and then gradually stabilizes.. The overall deformation is small, and the integrity of the sides is good. After stabilization, the sinking amount of the top plate is controlled within $10 \mathrm{~mm}$, and the convergence of the two sides is within $15 \mathrm{~mm}$. The thick-layer anchored rock beam constructed by long bolts fully mobilizes the performance of the deep rock mass inhibits the development trend of shallow cracks and has a better control effect.

(2)Monitoring the development of fissures in the roof surrounding rock

Two boreholes with a depth of $8.0 \mathrm{~m}$ were constructed at the construction mileage of $80 \mathrm{~m}$ and $260 \mathrm{~m}$ in the test section respectively, and the boreholes were characterized by the mine borehole imager. The borehole characteristics are shown in Fig. 15 below.

As shown in Fig. 15(a), the borehole Z-01 is located at $50 \mathrm{~m}$ in the test section. There is a broken layer at $0.5 \mathrm{~m}$ except for the shallow part of the roof. The rest of the area is relatively complete, and no cracks and separation are found.

As shown in Fig. 15(b), drill hole Z-02 is located at a mileage of $260 \mathrm{~m}$ in the test section. The roof is relatively intact. There is no obvious fracture and crack development zone. The top coal is thick. Above $6.0 \mathrm{~m}$, it is siltstone and coarse sandstone. The stratum has good lithology.

Based on the analysis of the above borehole images, there is no fracture zone, and only one detached fracture zone exists at a shallow surface of $0.5 \mathrm{~m}$, indicating that the existing $2.5 \mathrm{~m}$ bolt support length has broken through the shallow fracture zone and has achieved spanning. In addition, the stability of the roof has been systematically strengthened compared with the original support, and the safety of the roof has been realized.

(3) Roadway construction photos

The actual photo of the roadway of the new scheme is shown in Fig. 16. The roof and the two sides of the roadway are very flat with only slight deformation; the implementation of the new scheme not only ensures the control effect of the roadway but also improves the excavation efficiency and alleviates the problem of unbalanced mining and excavation.

\section{Conclusion}


(1)The time-effect characteristics of roof stress transfer during roadway excavation and the mechanism of high-pre-tension cross-boundary long-anchoring support are described. By increasing the length of bolts and initial pre-stress, and lengthening the thickness of anchoring, a wide range of surrounding rock can participate in the construction of thick anchored rock. Beam to ensure the safety and stability of the roadway. By reducing the support density, enlarging the bolt spacing, reducing the number of anchor cables, reducing the roof support time, achieving parallel operations of support cutting, and increasing the speed of roadway excavation. Combining the relevant geological conditions of the S1231 tunneling face of Caragana Tower, a low-density and high-preload cross-border support plan are proposed.

(2)Numerical simulation shows that during the tunneling period, the range of $5 \mathrm{~m}$ before and after the front is the period of stress fluctuation, the peak value of fluctuation is $5.3 \mathrm{Mpa}$, and the stress adjustment zone gradually transitions from the stress adjustment zone to the original rock stress zone beyond $5 \mathrm{~m}$. After the impact of secondary mining, the deformation of the roadway roof reaches its peak. The roof deformation is $10 \mathrm{~mm}$, the left side is $2.5 \mathrm{~mm}$, the right side is $7.5 \mathrm{~mm}$, and the bottom is about $2.5 \mathrm{~mm}$. The new support scheme reduces the deformation of the surrounding rock and achieves better results. Good control effect has been correctly verified for subsequent field tests.

(3)Field practice shows that the average sinking amount of the top plate is about $9 \mathrm{~mm}$, and the moving amount of the two sides is about $11 \mathrm{~mm}$. The cracks are controlled within $0.5 \mathrm{~m}$. The time for roof support in the circulation is shortened to 50 minutes, and the driving rate is increased to $1417.5 \mathrm{~m} / \mathrm{month}$ (double lanes), which is $77.19 \%$ higher than the original plan. It shows from the front that the cross-border support technology is increasing the anchorage length and improving the stability of the roadway. At the same time, by reducing the support density, the excavation rate has been greatly increased, and the contradiction between mining and excavation replacement has been alleviated, which provides an important reference for the efficient and rapid excavation of adjacent mining areas and mines with similar conditions.

\section{Declarations}

Due to technical limitations, Declarations section is not available for this version.

\section{References}

1. Feng X, Zhang N, Xue F et al (2019) Practices, experience, and lessons learned based on field observations of support failures in some Chinese coal mines, 123. INTERNATIONAL JOURNAL OF ROCK MECHANICS AND MINING SCIENCES, p 104097

2. Kan J, Li G, Zhang N et al (2021) Changing Characteristics of Sandstone Pore Size under Cyclic Loading. GEOFLUIDS2021

3. Kang H, Yang J, Gao F et al (2020) Experimental Study on the Mechanical Behavior of Rock Bolts Subjected to Complex Static and Dynamic Loads. ROCK MECHANICS AND ROCK ENGINEERING53(11):pp 4993-5004 
4. Li X, Zhang N, Xie Z et al (2019) Study on Efficient Utilization Technology of Coal Pillar Based on Gob-Side Entry Driving in a Coal Mine with Great Depth and High Production.

Sustainability11(6):1706

5. Liang D, Zhang N, Liu H et al (2021) Hybrid finite-discrete element simulator based on GPGPUparallelized computation for modelling crack initiation and coalescence in sandy mudstone with prefabricated cross-flaws under uniaxial compression. ENGINEERING FRACTURE MECHANICS247

6. Ma P, Qian D, Zhang N et al (2020) Application of Bolter Miner Rapid Excavation Technology in Deep Underground Roadway in Inner Mongolia: A Case Study. Sustainability12(7):2588

7. Tang B, Cheng H, Tang $Y$ et al (2020) Supporting Design Optimization of Tunnel Boring MachinesExcavated Coal Mine Roadways: A Case Study in Zhangji. China Processes 8(1):46

8. Wang G, Xu Y, Ren H (2019) Intelligent and ecological coal mining as well as clean utilization technology in China: Review and prospects. International Journal of Mining Science Technology 29(2):161-169

9. Xie Z, Zhang N, Feng X et al (2019) Investigation on the evolution and control of surrounding rock fracture under different supporting conditions in deep roadway during excavation period, 123. INTERNATIONAL JOURNAL OF ROCK MECHANICS AND MINING SCIENCES, p 104122

10. Xie Z, Zhang N, Qian D et al (2018) Rapid Excavation and Stability Control of Deep Roadways for an Underground Coal Mine with High Production in Inner Mongolia. Sustainability10(4):1160

11. Xie Z, Zhang N, Yuan Y et al (2019) Study on Safety Control of Composite Roof in Deep Roadway Based on Energy Balance Theory. Sustainability11(13):3688

12. Yang H, Han C, Zhang $\mathrm{N}$ et al (2019) Stability Control of a Goaf-Side Roadway under the Mining Disturbance of an Adjacent Coal Working Face in an Underground Mine. Sustainability11(22):6398

13. Yang H, Han C, Zhang N et al (2020) Research and Application of Low Density Roof Support Technology of Rapid Excavation for Coal Roadway. Geotechnical Geological Engineering38(1):389401

14. Yang H, Zhang N, Han C et al (2021) Stability Control of Deep Coal Roadway under the Pressure Relief Effect of Adjacent Roadway with Large Deformation: A Case Study. Sustainability13(8)

15. Yang S, Liu S, Zhang $N$ et al (2021) A fully automatic-image-based approach to quantifying the geological strength index of underground rock mass. INTERNATIONAL JOURNAL OF ROCK MECHANICS AND MINING SCIENCES140

\section{Figures}




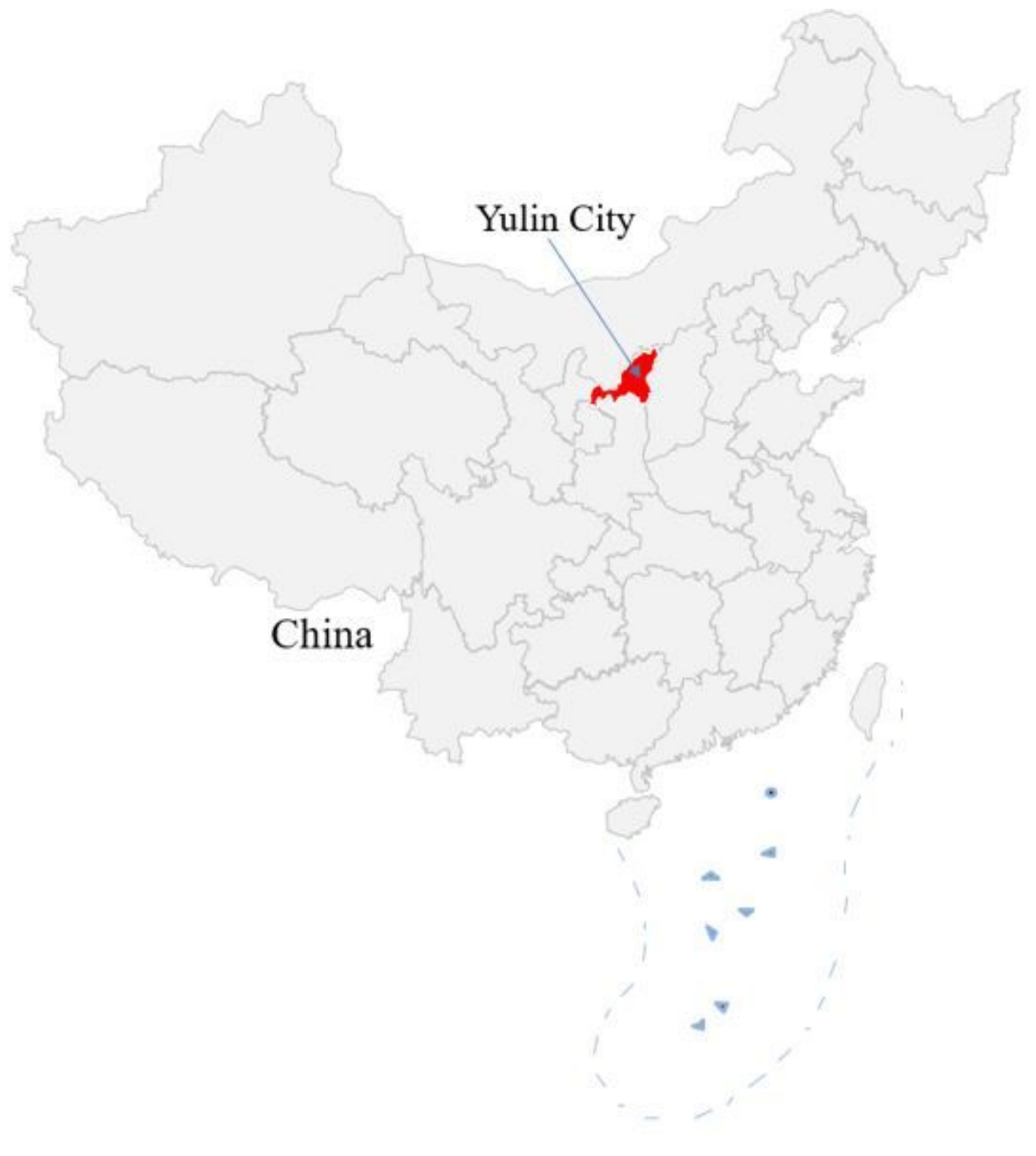

Figure 1

Geographic location map of the mine Note: The designations employed and the presentation of the material on this map do not imply the expression of any opinion whatsoever on the part of Research Square concerning the legal status of any country, territory, city or area or of its authorities, or concerning the delimitation of its frontiers or boundaries. This map has been provided by the authors. 


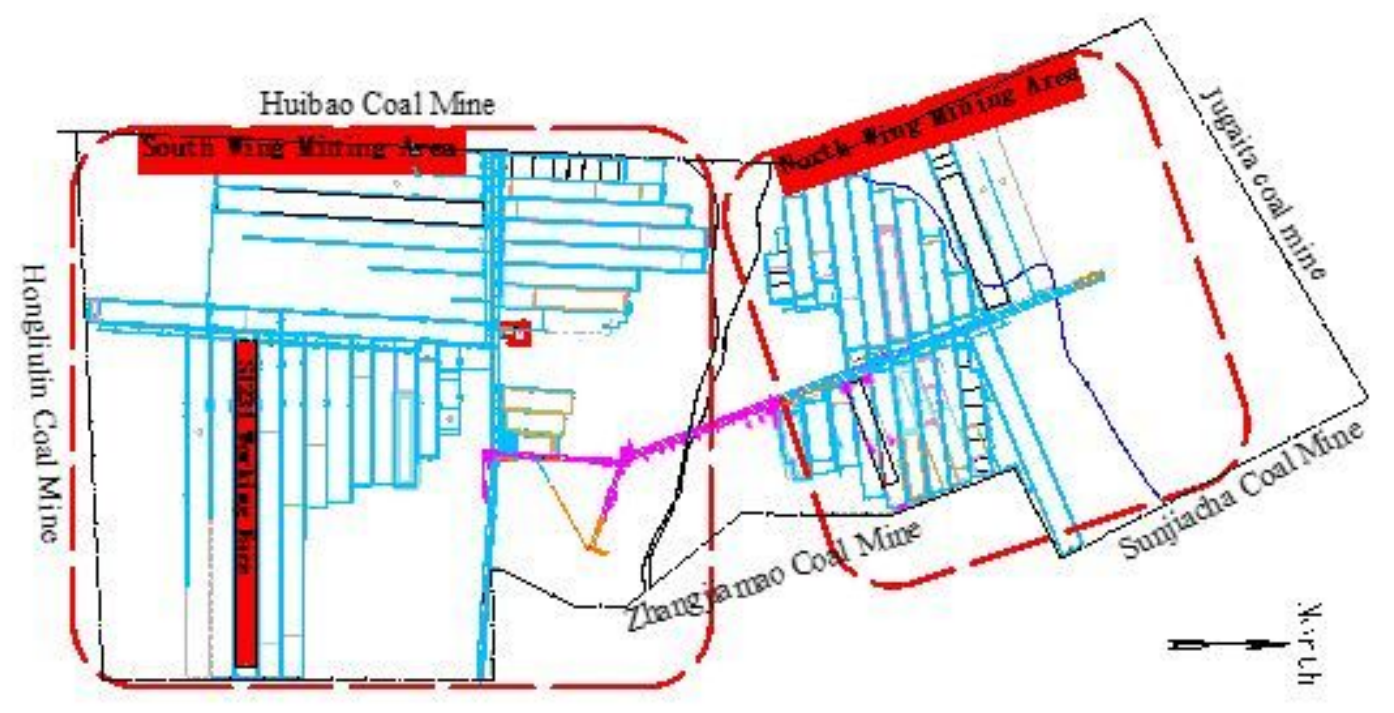

Figure 2

The overall position of the S1231 working face

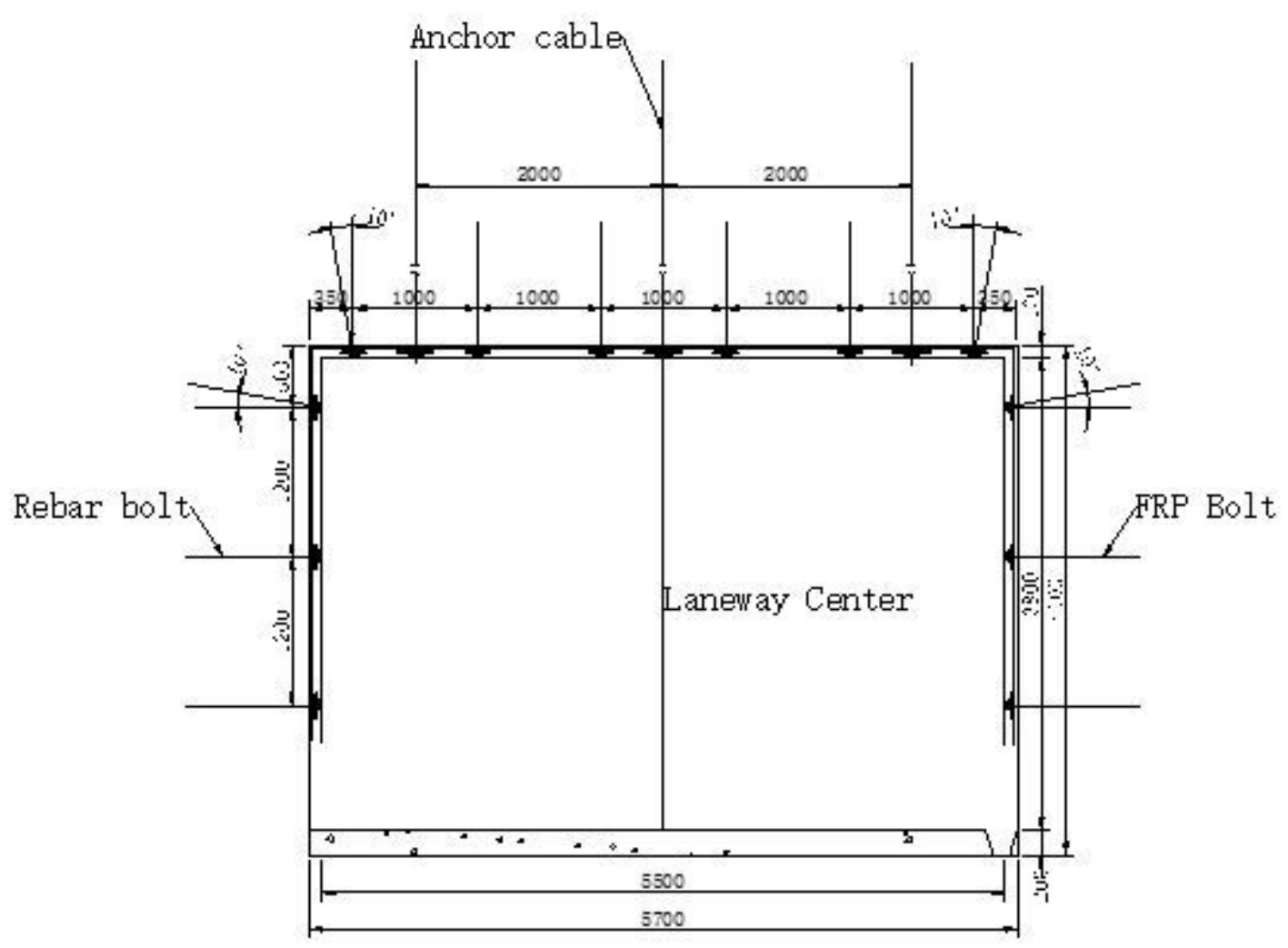

Figure 3

The original support scheme of S1231 auxiliary transport lane 


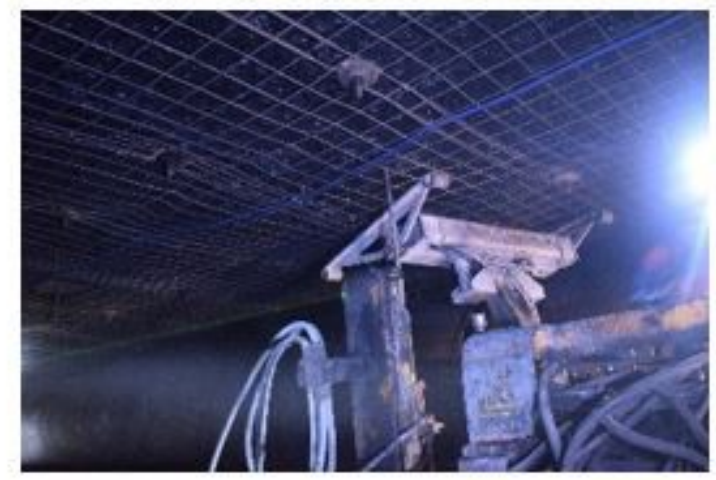

(a) Roof anchor cable construction

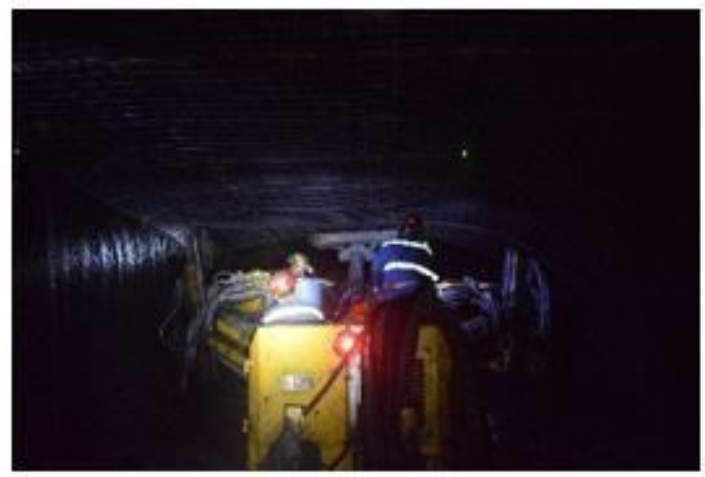

(b) Roof support situation

Figure 4

On-site picture

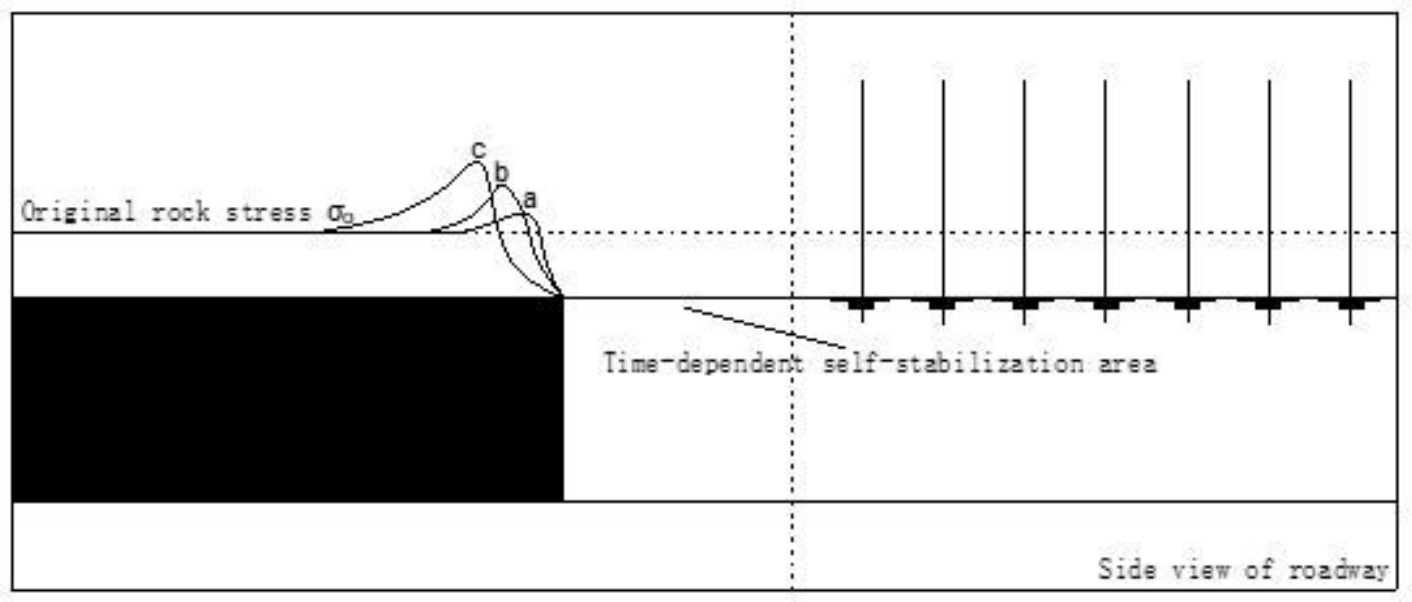

Figure 5

Time-effect force driving characteristics of driving face(Zhang et al.2019)

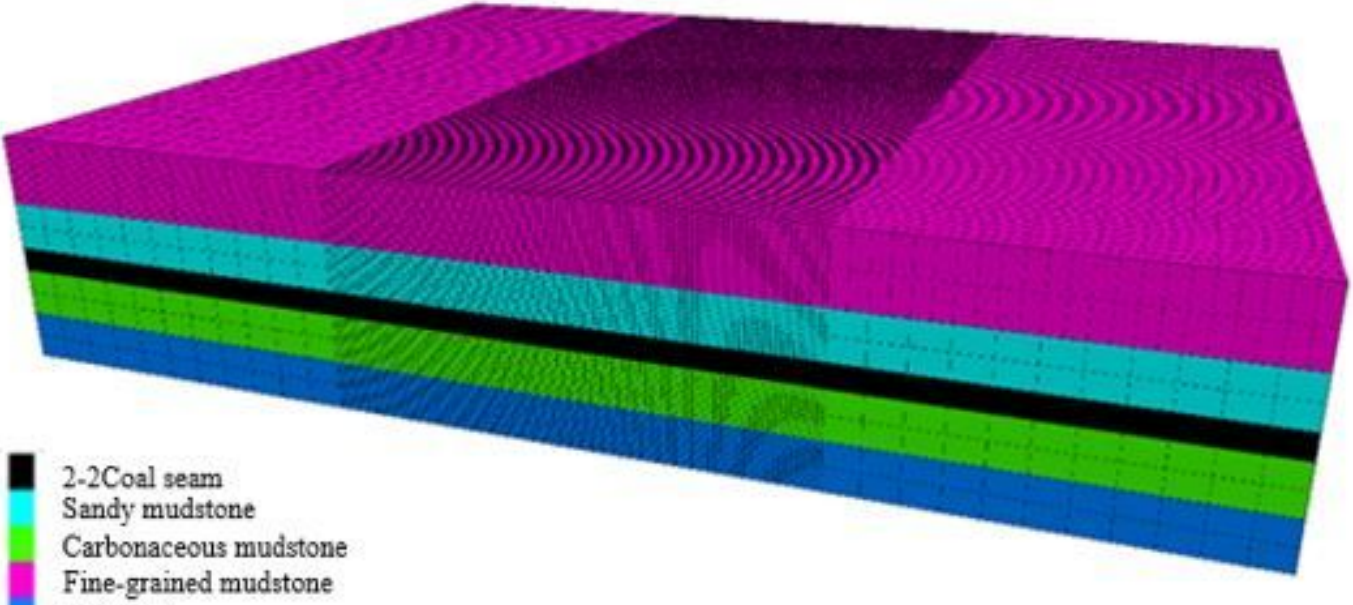

Fine-grained mudstone

Siltstone 
Figure 6

Numerical calculation model

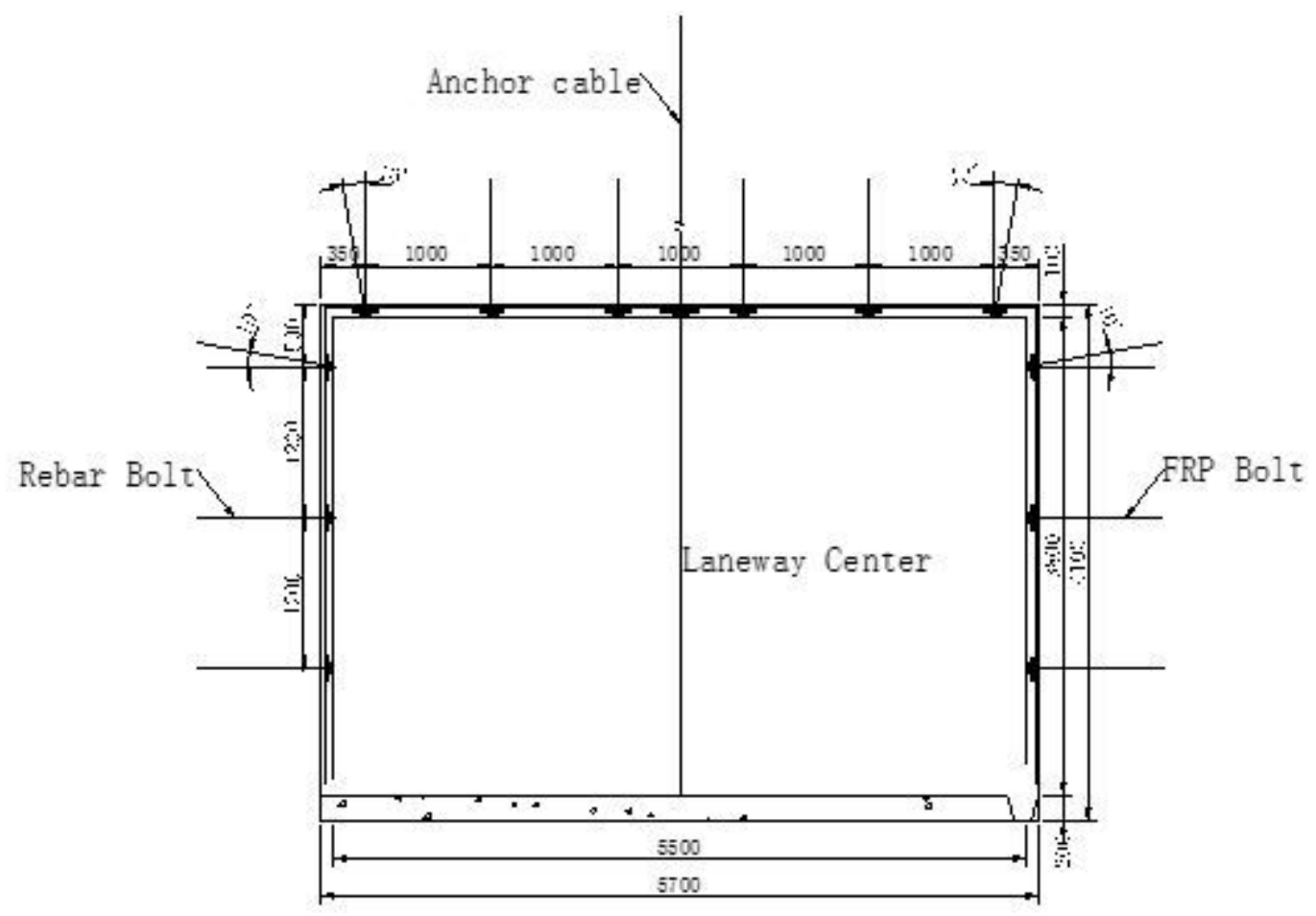

\section{Figure 7}

Low-density cross-border support parameter map

5. $1450 E+04$

$0.0000 E+00$

$-5.0000 \mathrm{E}+05$

$-1.0000 E+06$

$-15000 \mathrm{E}+06$

$-2.0000 \mathrm{E}+06$

$-2.5000 \mathrm{E}+06$

$-30000 \mathrm{E}+06$

$-3.5000 \mathrm{E}+06$

$-4.0000 \mathrm{E}+06$

$-4.5000 E+06$

$-5.0000 E+06$

$-5.5000 \mathrm{E}+06$

$-6.0000 \mathrm{E}+06$

$-6.5000 \mathrm{E}+06$

$-6.6262 \mathrm{E}+06$

\section{Figure 8}

Vertical stress distribution of roof when driving $90 \mathrm{~m}$ 


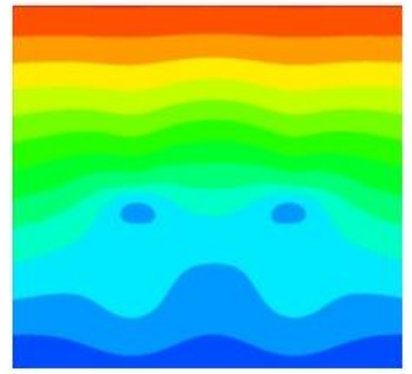

(a) Front $5 \mathrm{~m}$

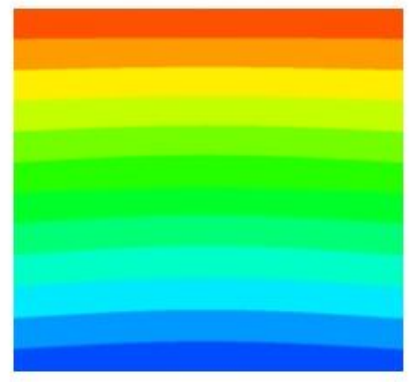

(c) Front $25 \mathrm{~m}$

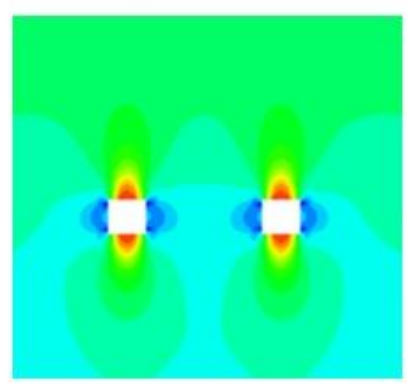

(e) Rear $5 \mathrm{~m}$

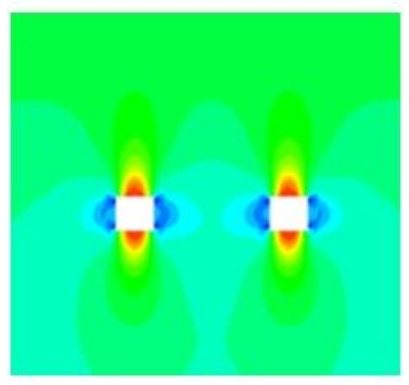

(g) Rear $25 \mathrm{~m}$

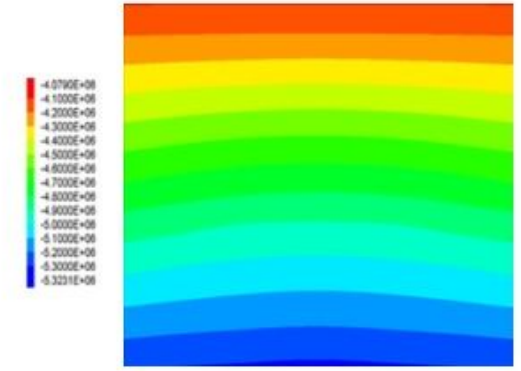

(b) Front $15 \mathrm{~m}$

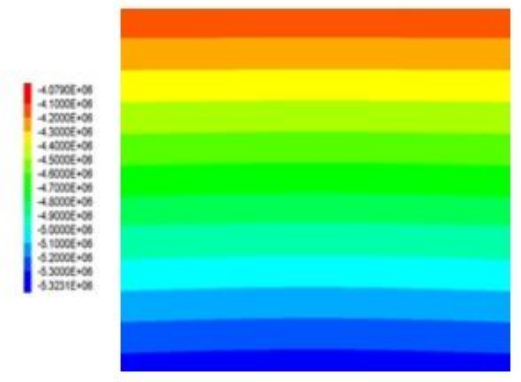

(d) Front $35 \mathrm{~m}$

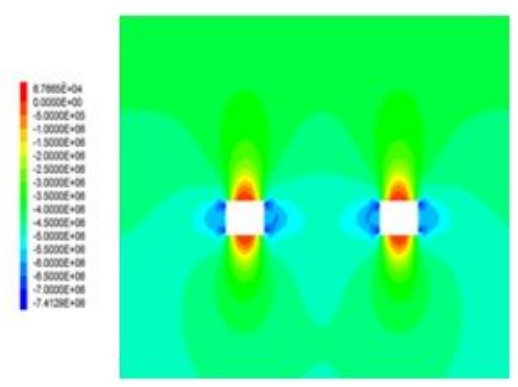

(f) Rear $15 \mathrm{~m}$

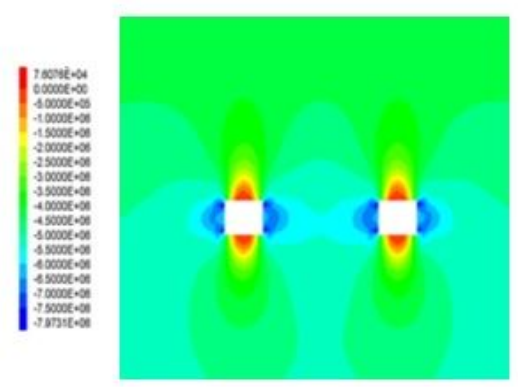

(h) Rear $35 \mathrm{~m}$

\section{Figure 9}

Vertical stress distribution at different head-on positions when driving $90 \mathrm{~m}$ 


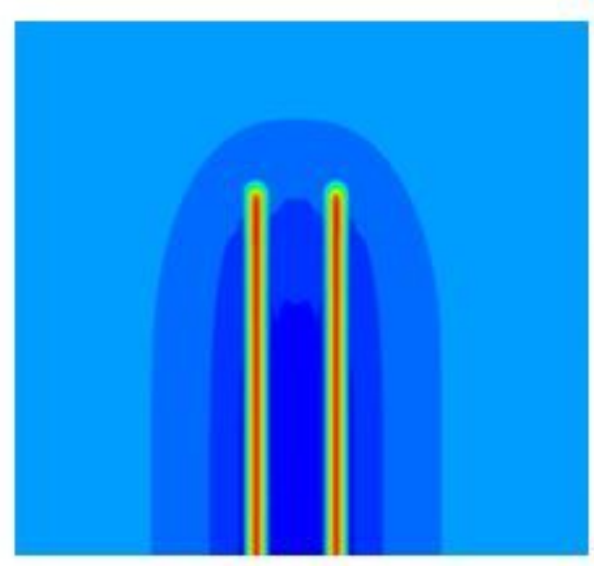

(a) $1.5 \mathrm{~m}$

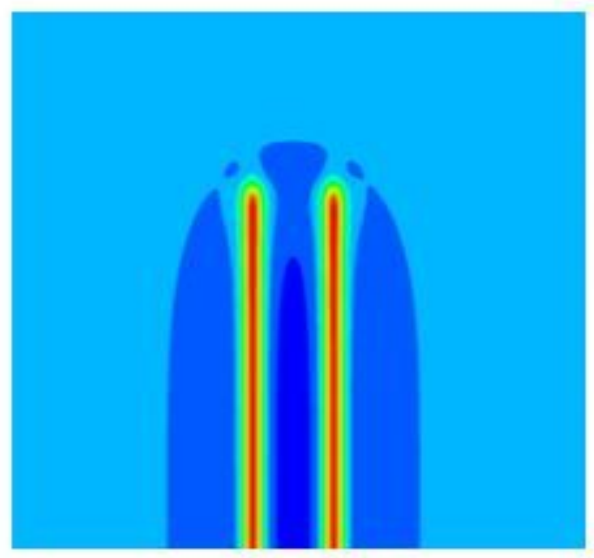

(c) $3.5 \mathrm{~m}$

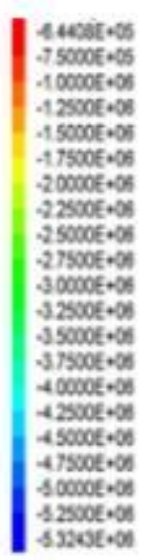

5.32400

(b) $2.5 \mathrm{~m}$

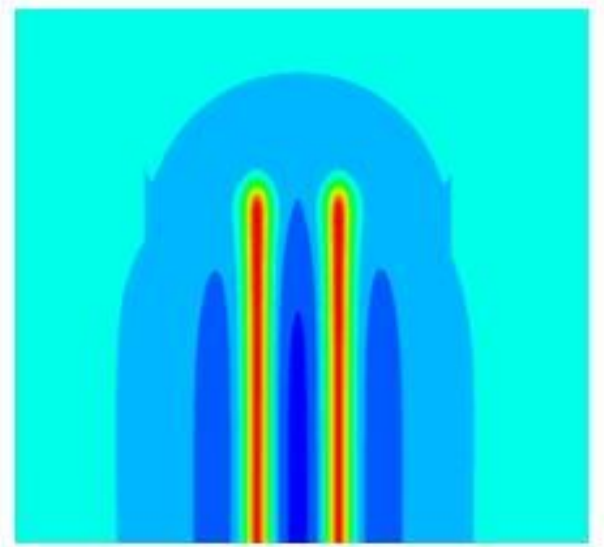

(d) $4.5 \mathrm{~m}$

\section{Figure 10}

Changes in vertical stress at different positions above the head-on roof during a 90m tunneling

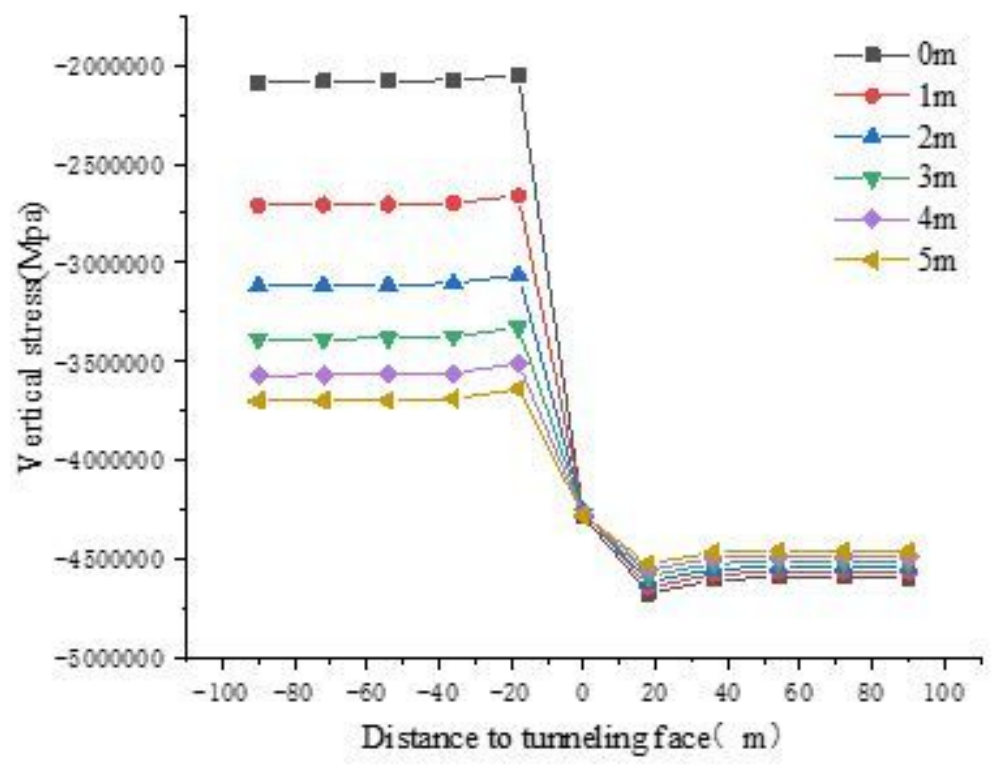




\section{Figure 11}

Stress measurement lines at different positions above the roof of the roadway when driving $90 \mathrm{~m}$

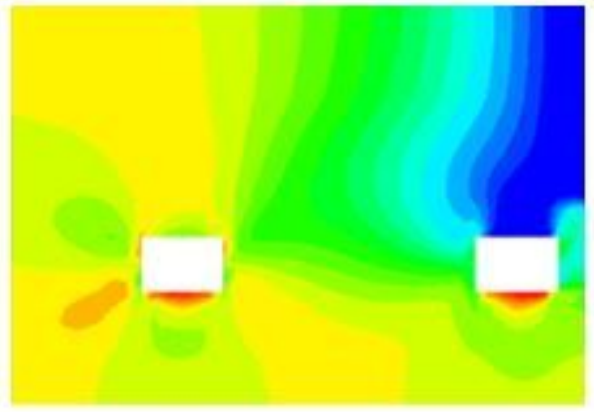

(a) Roadway vertical displacement

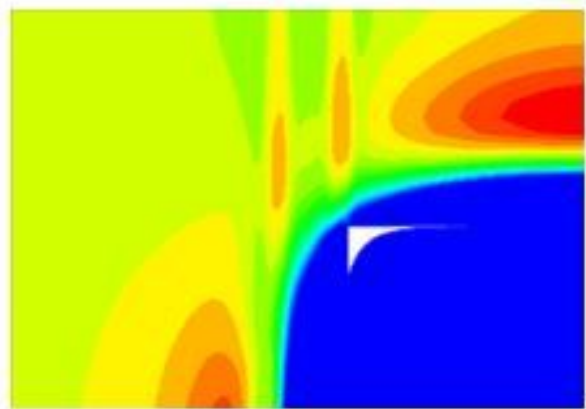

(b) Vertical displacement of top plate

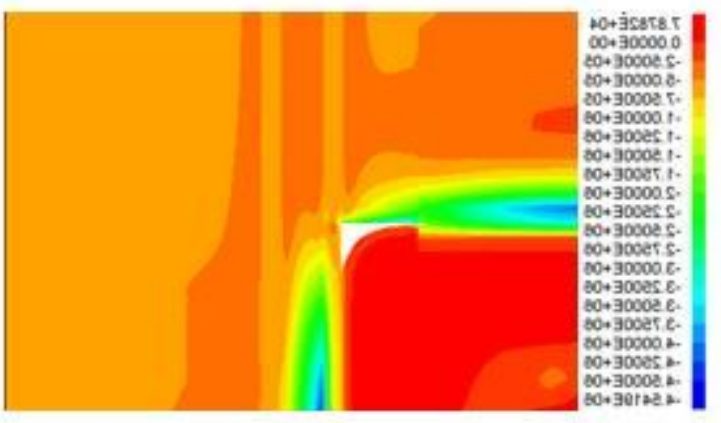

(c) Roadway vertical stress

\section{Figure 12}

Cloud map of roadway displacement changes after one mining 


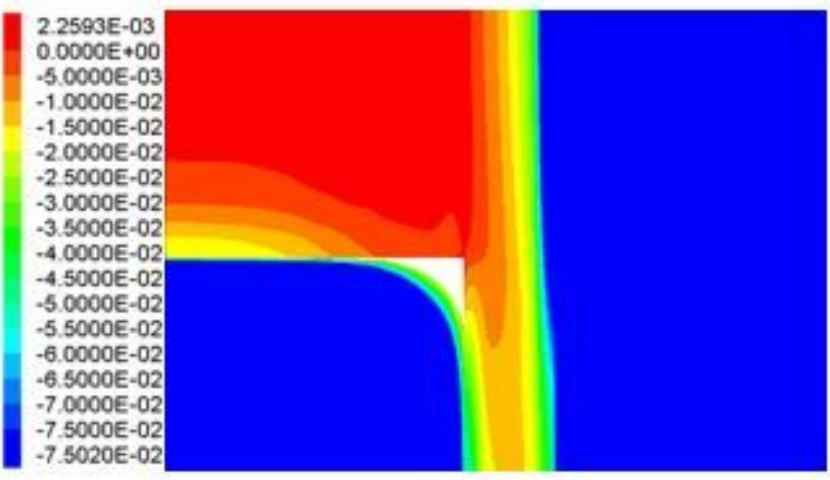

(a) Top plate displacement change

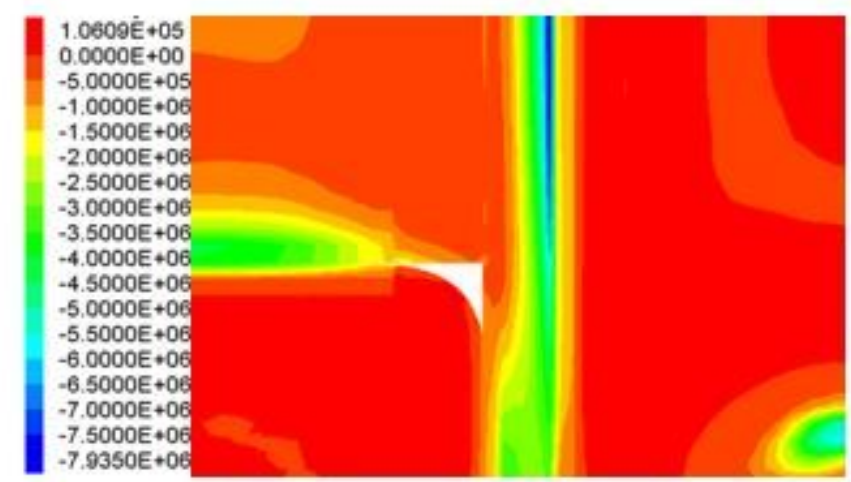

(b) Two-dimensional change of vertical stress

\section{Figure 13}

The vertical stress-displacement changes of the roof during secondary mining 


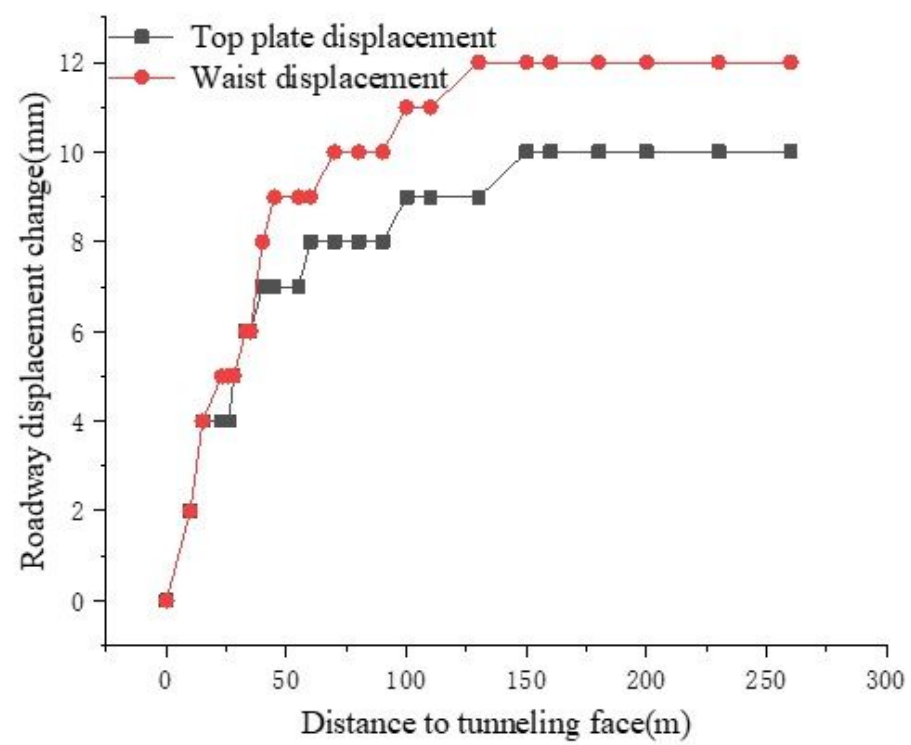

(a) Surface displacement monitoring data of W1 station

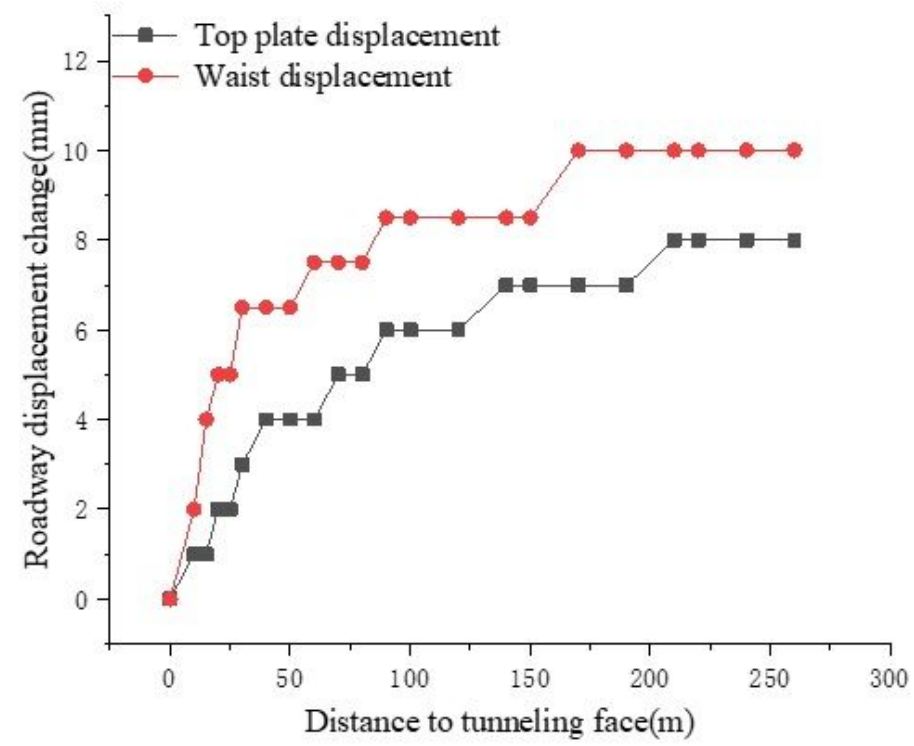

(b) Surface displacement monitoring data of W2 station

\section{Figure 14}

Surface displacement and deformation characteristics of the test section 

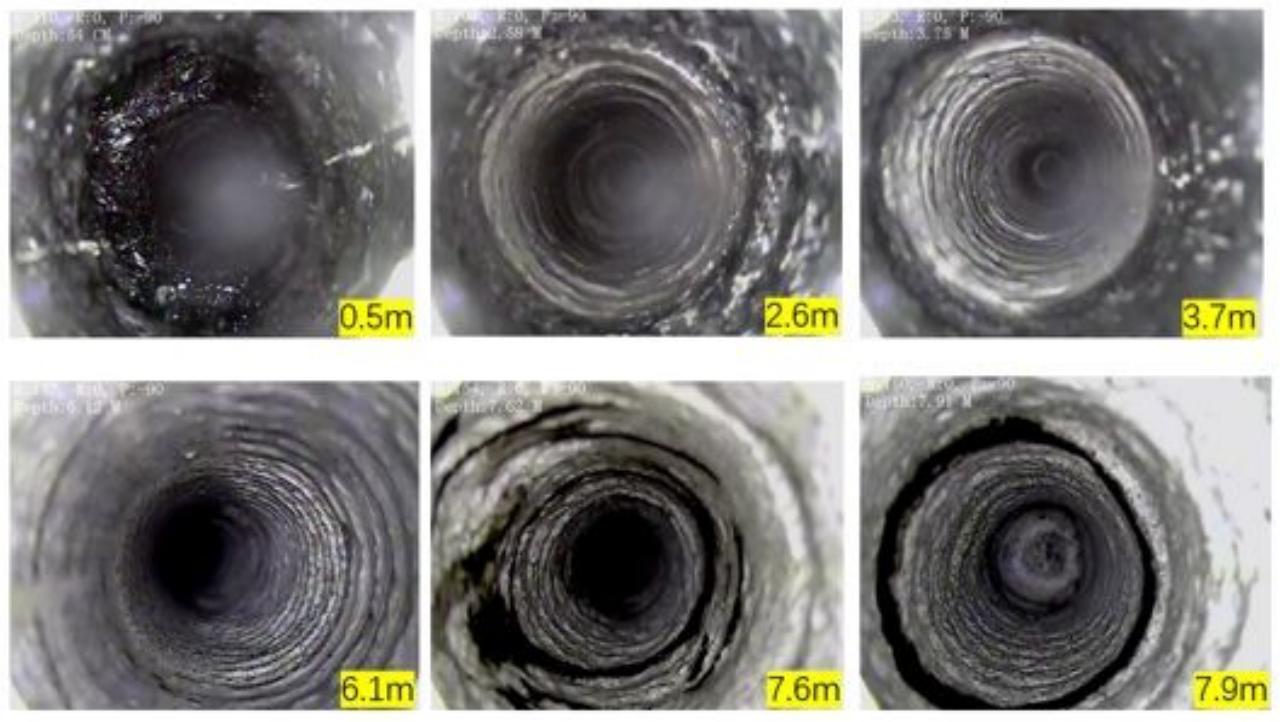

(a)Z-01
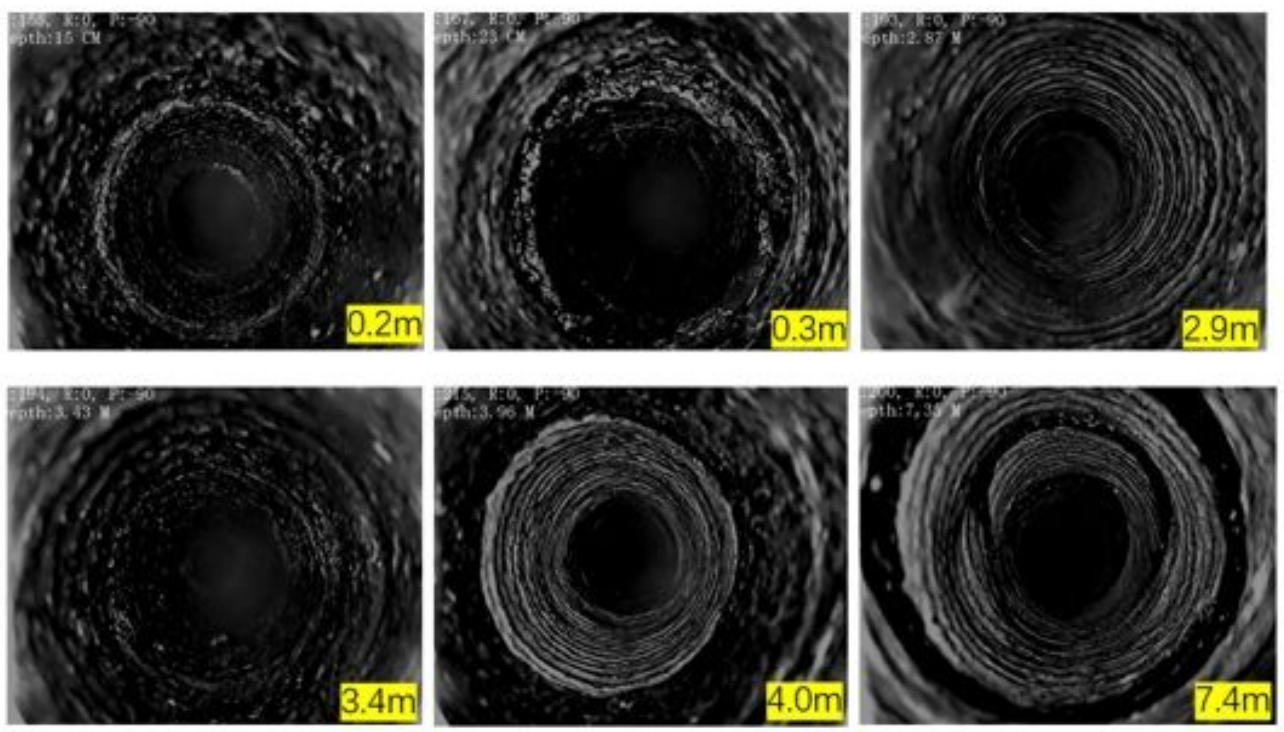

(b)Z-02

\section{Figure 15}

Drilling characteristics of the roof of the test section 


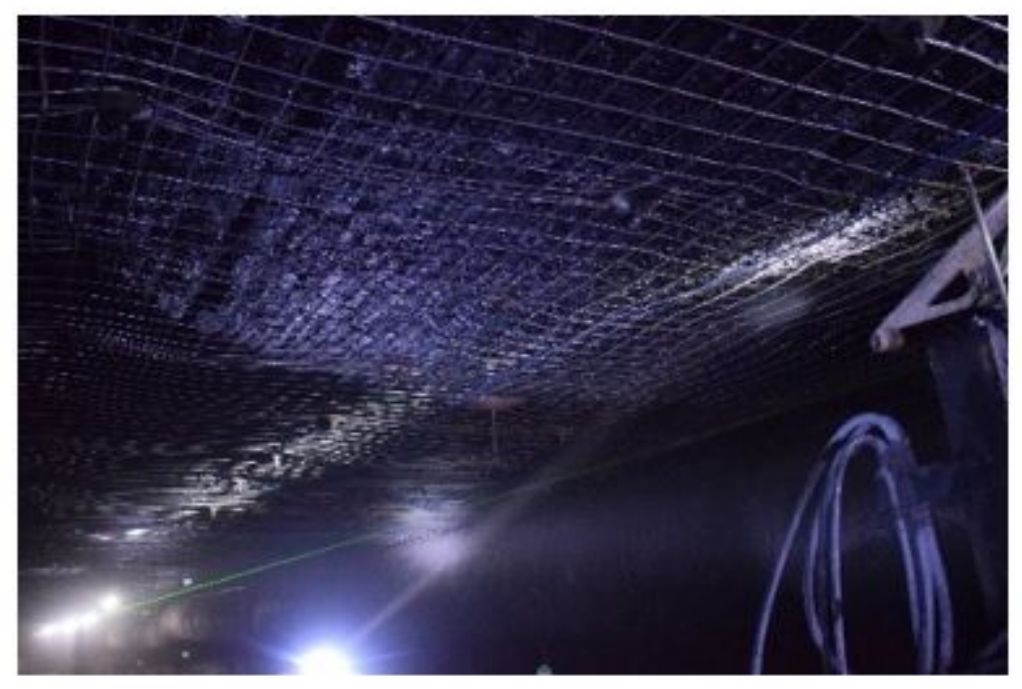

(a) Roof support

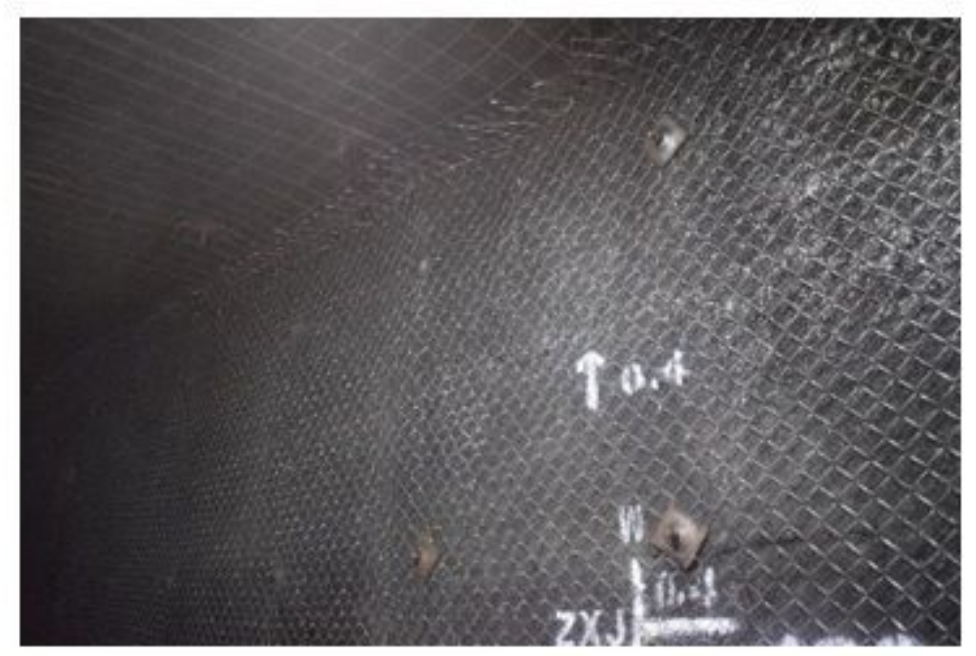

(b) Gang support

Figure 16

The actual photo of the supporting effect of the test section 